\title{
1 Adjusting to Retirement from Sport: Narratives of Former Competitive
}

\section{Rhythmic Gymnasts}

3 Francesca Cavallerio ${ }^{\mathrm{a}}$, Ross Wadey ${ }^{\mathrm{b}}$, Christopher R. D. Wagstaff ${ }^{\mathrm{c}}$

$4 \quad{ }^{a}$ Department of Life Sciences, Anglia Ruskin University, Cambridge, UK

$5 \quad{ }^{b}$ School of Sport, Health and Applied Science, St Mary's University, Twickenham, UK

$6 \quad{ }^{c}$ Department of Sport and Exercise Science, University of Portsmouth, Portsmouth, UK

8 Anglia Ruskin University, East Road, Cambridge, CB1 1PT, UK

9 St Mary’s University, Waldegrave Road, Strawberry Hill, Twickenham, TW1 4SX, UK

10 University of Portsmouth, Spinnaker Building, Cambridge Road, Portsmouth, PO1 2ER, UK

12 Francesca Cavallerio (corresponding author): Francesca.Cavallerio@anglia.ac.uk

Notes on contributors

Francesca Cavallerio is a Lecturer in Sport Psychology at Anglia Ruskin University, in the

Department of Life Sciences. Her research interest focuses on investigating athletes’ and coaches’ experiences and well-being in elite youth sport, using qualitative research methods.

Ross Wadey is a Senior Lecturer in Sport Psychology at St Mary's University. Ross Chair's the Psychology of Injury and Well-Being research group, which aims to conduct research on the prevention of and psychosocial recovery from injury.

21 Christopher R. D. Wagstaff is a Principal Lecturer in Sport Psychology at the University of

22 Portsmouth, and is a HCPC Registered Practitioner Psychologist. Chris has published widely in the 
1 area of organisational psychology in sport, with projects relating to four areas: employee emotions

2 and attitudes, stress and well-being, organisational behaviour, and high performance environments. 


\section{Adjusting to Retirement from Sport: Narratives of Former Competitive}

\section{Rhythmic Gymnasts}

\section{Abstract}

4 This study used narrative inquiry to understand the retirement experiences of rhythmic

5 gymnasts. Eight female former competitive gymnasts ( $M$ age $=24.5, S D=8.33$ ) each

6 participated in four life-history interviews. Following dialogical narrative analysis, three

7 narrative typologies were outlined: Entangled Narrative, Going Forward Narrative, and

8 Making Sense Narrative. The entangled narrative shows an individual with a monological

9 athletic identity, who is unable to develop a new identity following her retirement to the

10 detriment of her well-being, and wishes to return to being a gymnast. The going-forward

11 narrative describes those former gymnasts who were able to develop multiple identities

12 during their gymnastics career, and are now flourishing in their life post-retirement. The

13 making-sense narrative is an emergent narrative, which transcends the previous two

14 narratives. Findings expand narrative research by providing new narrative resources to

15 understand the experience of retirement from gymnastics. These narrative resources might

16 assist gymnasts to expand their narrative repertoire by raising awareness of different

17 narratives available in their culture.

$18++$

19 Keywords: athletic retirement, narrative analysis, life story, rhythmic gymnastics, well-

20 being 


\section{Introduction}

Retirement from sport can bring about dramatic changes to the social and psychological worlds athletes inhabit (Lally 2007). These changes can pose significant challenges to former athletes, such as a crisis of identity, relationship conflicts and breakdown, and adapting to cultures away from the high performance socio-cultural realm (e.g., Barker-Ruchti and Schubring 2016, Kerr et al. 2006,). Barker-Ruchti and Schubring (2016) argued that the process of adjusting to these challenges is typically not an acute event with a clear beginning and end, but a process that unfolds over time. Indeed, it is likely that this experience might possibly have chronic implications, which go beyond the immediate period following retirement from sport, such as depression, eating disorders, and substance abuse (e.g., Alfermann 2000, Kerr and Dacyshyn 2000, McKenna and Thomas 2007). Therefore, it is important that researchers not only consider the immediate aftermath following retirement, as done in previous studies (e.g., Lally 2007, Lavallee and Robinson 2007, Warriner and Lavallee 2008), but also seek to gain a better understand of the ongoing social and psychological adjustment to life after sport.

During their sport careers, athletes inhabit certain social and psychological worlds.

Findings from Cavallerio et al. (2016) illuminated how young rhythmic gymnasts were immersed in the cultural environment of an elite gymnastics club. Over time, the gymnasts learned and accepted the values (e.g., importance of success, discipline) and norms (e.g., do not skip training, do not talk back to the coach, be on time) that characterised their environment, in the pursuit of being 'good gymnasts' (Cavallerio et al. 2016). Indeed, rather than disclosing their experiences of pain and injury to their coaches, the gymnasts in Cavallerio et al.'s study typically suppressed their pain, adopting behaviours that they believed to be better aligned with the cultural values of the sport organisation (e.g., keep working hard without stopping to complain) and engaged in wishful thinking that their pain 
1 would go away. This lack of open communication between athletes and coaches, together

2 with pain normalisation and impression management behaviours, was shown to influence the

3 development of overuse injuries. Overall, the gymnasts adhered to the cultural values and

4 norms inherent within the gymnastics environment by displaying appropriate behaviours

5 reinforced by the coach (Cavallerio et al. 2016). The extant research exploring the

6 environment of gymnastics has advanced our understanding of the role of culture in the

7 experience of current gymnasts. Nevertheless, what remains unknown is what happens to

8 these gymnasts - who have given so much to their club and to the gymnastics environment -

9 once they retire and leave that same environment. There also remains a dearth of knowledge

10 regarding how gymnasts' social and psychological worlds change following retirement, how

11 they adjust to these changes, and what resources are available to them. Addressing these gaps

12 in knowledge will provide important insights into how sport science and medicine can help

13 improve the life long-term well-being of former gymnasts.

14 Several studies have highlighted retirement from gymnastics to be a highly stressful

15 experience (e.g., Clowes et al. 2015, Lavallee and Robinson 2007, Warriner and Lavallee

16 2008). Specifically, previous researchers have demonstrated that one of the most significant

17 challenges for gymnasts was their search for a new identity (e.g., Kerr and Dacyshyn 2000,

18 Lally 2007). Kerr and Dacyshin (2000) and Stirling et al. (2012) suggested that having

19 typically engaged in gymnastics from a very young age, gymnasts did not have sufficient

20 time and opportunities to develop alternative identities, therefore developing an identity

21 solely based on their role as athletes. Yet, while these findings provide us with a good

22 understanding of some of the psychological challenges experienced by gymnasts following

23 retirement, they pay little attention to their social worlds and how they may shape their

24 thoughts, feelings and behaviours. By better understanding the socio-cultural domain, it will

25 provide a more complete understanding of gymnasts' psychological experiences, and how 
1 best to help them through this challenging life transition (cf. McGannon and Smith 2015). Researchers in the discipline of sport and exercise psychology have recently taken an

3 interest in the intersection between psychology and sociology in order to provide a

4 contextualised understanding of the influence of socio-cultural phenomena on athletes'

5 psychological experiences. One approach that has been effective in such endeavours is

6 narrative inquiry (McGannon and Smith 2015). The main characteristic of narrative inquiry is

7 that it focuses on an individual's stories and their unfolding nature over time (Smith 2010).

8 Stories have been recognised as one primary way people give meaning to life experiences

9 (e.g., Douglas and Carless 2009a, McAdams 1993). As Frank (2010) stated, 'stories work

10 with people, for people, and always stories work on people, affecting what people are able to

11 see as real, as possible, and as worth doing or best avoided' (p. 3). McLeod (1997) argued

12 that although personal stories prioritise an individual's experience, they also take place inside

13 a cultural and social environment, which is reflected in the narrative script adopted among

14 those available in their socio-cultural context (McLeod 1997). Therefore, adopting a narrative

15 approach allows researchers to focus both on the personal and social, without losing the

16 complexity of human life (Crossley 2000). Narrative inquiry also offers an insight into the

17 trajectory of an individual's life (see Lieblich et al. 1998), thereby enabling researchers to

18 better understand how experiences evolve over the life course (e.g., retirement from sport).

19 In an attempt to extend previous research exploring gymnasts’ psychological

20 experiences of retirement from sport, this study aims to gain an insight to and understanding

21 of the psychosocial adjustment of competitive rhythmic gymnasts to retirement. To achieve

22 this, we adopted a narrative approach, focusing on the life stories of former rhythmic

23 gymnasts, who trained and competed at an elite level in Italy.

\section{Method}




\section{$1 \quad$ Philosophical assumptions and methodology}

3 (i.e., there is a multiple and mind-dependent reality) and epistemological constructionism

4 (i.e., we construct knowledge in a subjective way). In line with these assumptions, narrative

5 inquiry was the chosen approach to collect and analyse data, as it offers the chance to explore

6 an individual's stories and allows for consideration of the relational and cultural construction

7 of them (Smith 2016). Indeed, not only does narrative inquiry have the capacity of offering

8 information about the personal world of athletes and the meanings behind their experiences,

9 but it also offers insights on how people create their stories.

\section{Participants and procedure}

Following institutional ethical approval, 10 former gymnasts were contacted via email and were presented with an outline of the research project. The gymnasts all came from an elite Italian rhythmic gymnastics club, which had been consistently among one of the highest performance clubs within the Country in the past 20 years. Selection criteria included having trained at competitive level in the club and having retired from gymnastics. Nine out of the initial ten former athletes agreed to participate, but one had to withdrew after a severe accident. This resulted in eight female former competitive gymnasts $(M$ age $=24.5, S D=$ 8.33), all of whom had competed at a national level and won titles. Time since retirement ranges from 1-to-17 years at the time of this study ( $M$ years $=5.87, S D=5.86)$.

In line with narrative inquiry, interviews were deemed the most appropriate method to collect participants' stories of gymnastics and life after gymnastics. We adopted short-life history interviews (Plummer 2001), which focus on key moments in the life of the interviewee that are linked with the topic of the research. The term life history has often been used interchangeably with life story, even though they have different meanings (Sparkes and Smith 2014). While scholars described the former as having a focus on and a link with the history 
1 and politics of a specific time (Plummer 2001), the latter is defined as drawing on people's

2 experiences, assuming individuals construct their identities by narrating stories about

3 themselves (McAdams et al. 2013). The present study adopted this second stance, whereby

4 the participants recounted chapters of their life during the interviews, thereby offering a

5 window into their experiences (McAdams 2001). Before starting to interview the participants,

6 a pilot short-life history interview was conducted with another former gymnast from a

7 different club. The pilot data were not included in the analyses. Next, participants completed

8 four separate one-to-one interviews to collect their short-life history. The meetings took place

9 in a quiet public place. A total of 32 interviews were conducted and they each lasted

10 approximately 45 minutes $(S D=10.14)$, with a total interview time of about 3 hours per

11 participant. For each participant, interviews built upon one another, following a chronological

12 order. The first three interviews focused respectively on: (a) the participant's past experience as a gymnast; (b) their present situation, reflecting their retirement from gymnastics, and; (c)

14 the future, and whether the interviewee anticipated her gymnastics experiences to affect it.

15 Before each of the second, third, and fourth interviews with each participant the first author

16 listened to their previous interviews and made notes on questions to follow up with the

17 participants before we focused on new topics (e.g., 'Could you give me an example of...',

18 'Could you explain this situation further?’).

Following the first three meetings, interviews were transcribed verbatim. The

20 transcripts were sent back to each participant, with the request to read them before the last

21 meeting. During the fourth interview participants were given the chance to clarify any points

22 in their story from the previous interviews (McAdams 2008). When the participants and

23 interviewer felt there was no more information, thoughts or reflections to add on the topic in

24 question, the researchers considered data saturation to be reached in terms of the individual

25 short-life stories (O’Reilly and Parker 2013). Despite reaching saturation, we acknowledge 
1 that the findings might only represent a partial insight into the participants' full, rich, and

2 lived lives, as '...to the extent that each life is unique, no data are ever truly saturated: there

3 are always new things to explore' (Wray et al. 2007, p. 1400).

There were several benefits in conducting separate interviews (Atkinson 1998).

5 Despite being time consuming in terms of overall length of the study, four shorter interviews

6 were easier to fit into the busy schedules of the participants, and were also less taxing for

7 them compared to a longer one. Moreover, they gave the researcher and the participants the

8 opportunity to reflect between interviews, which resulted in the chance to ask follow-up

9 questions and invite the participants to reflect on their experiences, offered by the four-

10 meeting interview process, was paramount. In doing so, it is our belief that we were able to

11 collect richer and more in-depth data than using a single interview procedure, thereby reaching a more complex understanding of participants' stories. Further, over the time-span of the four interviews, the participants and interviewer had substantial time to transact with each other and develop a rapport characterised by trust and familiarity. This relationship was further strengthened by drawing on the interviewer's own experiences as a former competitive gymnast and current role as a rhythmic gymnastics coach. Indeed, we feel these experiences allowed the first author to combine a narrative inquirer's scholarly curiosity with an empathic stance toward participants' experiences. Overall, we feel this insider status to the sport culture and to life after gymnastics increased the participants' openness and facilitated trust and rapport throughout the whole interview process (Carless and Douglas 2013a). Throughout the data collection process, the authors had weekly meetings, giving the chance to reflect on and discuss each interview, the data collected, the first author's relationship with the interviewees, and on our role as researchers in the construction of

24 knowledge. Being an insider to the gymnastics culture and the club environment also meant the first author had to carefully avoid imposing her own values, beliefs and perceptions, 
1 while encouraging the participants not to withhold any information by taking similarities for

2 granted (Berger 2015). The role of the second and third authors as 'critical friends' at this

3 stage increased the rigour of the data collection process. This was particularly important

4 when it came to understanding and interpreting the gymnastics culture. What was initially

5 considered 'normal' by the first author was challenged by the co-authors. This allowed the

6 first author to reflect on her beliefs and assumptions, and better consider these during the data

7 collection and analysis processes, and which would have perhaps otherwise gone unnoticed.

\section{Analysis and representation}

Narrative analysis has been described as an umbrella term for different methods that allow researchers to make sense, interpret and represent people’s stories (Sparkes and Smith 2014). There are various theoretical approaches to narrative analysis, and the one adopted in this study is called narrative contructivism. It takes into account the participants’ personal stories, but also the socio-cultural environment surrounding the individuals (Smith 2016). The focus here is not only on the story told by the participant, but on what the story does to and for the storyteller (Frank 2010).

We analysed the participants’ stories through the lens of dialogical narrative analysis (DNA). DNA is considered a flexible analytical method that allows for movement of thought (Frank 2012). This type of analysis examines what is said in a story, what the narrative resources used in its structure are, what the story does, and why an individual chooses a particular story to represent her life (Caddick 2016). To this end, the process of analysis began with an initial immersion in the data, firstly by transcribing and then by reading and rereading the interviews. Next, the first author added notes to the transcripts, identifying stories, themes, and structures, and highlighting the parts of the text that related to the research question. We then considered the data by asking dialogical questions (Frank 2012), 
1 circulating and affiliation questions (e.g., Who tells which stories to whom? Who is part of

2 the in-group? Who will be in the out-group through this story?), identity questions (e.g., How

3 does this story tell people who they are?), and function questions (e.g., What does this story

4 do for and on the person?). These questions helped to illuminate the effects that the stories

5 had on their storytellers and their lives. Dialogical questions also allow researchers to identify

6 social, cultural and relational dynamics in the stories, by reflecting on how a story shapes its

7 storyteller's identity, and on what the cultural narrative resources underlying the individual

8 stories are (Caddick 2016). Once the analysis was concluded, we chose to structure the

9 results around typologies of stories. A narrative type has been defined as, 'the most general

10 storyline that can be recognised underlying the plot and tensions of particular stories' (Frank

11 2013, p. 75). According to Frank (2013), the stories people tell are unique yet based on an

12 adaptation and combination of the narrative types available in their culture. Examining the

13 different narrative types allowed us to gain a deeper understanding of how the culture of

14 gymnastics influenced and informed former athletes' personal stories of their life after

15 retirement.

16 Findings and Discussion

Results from this study are presented alongside the discussion section, and integrate both participants’ quotes and analytical interpretations. By adopting this way of presenting and discussing results, our aim is to provide a more transparent connection between participants' stories and existing knowledge. The analysis conducted revealed three types of

21 post-retirement narratives: Entangled, Going Forward, and Making Sense. The essential storyline of the Entangled Narrative is 'I was a successful gymnast. I am not a gymnast anymore. I want to be a gymnast again'. The storyline of the Going Forward Narrative is 'I was more than just a gymnast. I am more than a former gymnast. I look forward to what the future holds'. The final storyline refers to the Making Sense Narrative. This narrative differs 
1 from the previous two due to its emergent quality. Smith (2013) described emergent

2 narratives as being open to anything life brings. Differently from the other narratives, the

3 emergent one is lacking a real plot and can be considered a protonarrative (i.e., the beginning

4 of a narrative; Smith 2013). It is productive, optimistic, and open, with its main focus on the

5 present.

6 In the stories of the participants from this study there is a narrative tension spanning

7 from memories and values from the past and the comfort of the 'known' (e.g., life in the

8 gym), and a general openness to new, undefined - and possibly not yet imagined -

9 possibilities. Figure 1 illustrates the three narrative typologies, with a particular focus on the

10 making sense narrative and its potential development toward the unknown of the going

11 forward narrative, or withdrawal into the past of the entangled narrative. In the following pages, and in line with previous narrative studies (e.g., Carless and Douglas 2013b; Phoenix and Smith 2011), three exemplar cases, one for each type of narrative, are presented: namely

14 those of Diana, Giorgia, and Elisabetta.

[Figure 1 here]

Figure 1. Narrative typologies of former competitive gymnasts.

\section{The Entangled Narrative: Diana's story}

Diana lives in the past. Although she quit gymnastics four years ago, she finds it hard to let go and still refers to herself as a gymnast. She experienced substantial success in her gymnastics career, winning several regional, inter-regional, and national titles; she is proud of

21 those awards and of the representative trophies that remind her of all her past accomplishments and of happier times in her life. Diana was, and still is, passionate about

23 gymnastics. She lived and breathed gymnastics during her childhood and adolescent years.

24 Any time away from school was spent in the gym, and when she was not in the gym she 
1 would daydream about becoming a champion. She looks back at those days with fond

2 memories, which make her feel good about herself; a feeling of self-acceptance and purpose

3 in life. Nevertheless, now she is retired she feels lost, confused, and finds it challenging to 'fit

4 in' with social groups outside of her gymnastics environment. Her focus is in the past and if

5 she had one wish, she would love to relive her gymnastics career, when she was winning

6 national events.

$7 \quad$ Interviewer: So you'd be ready to put your leotard on and go back?

8 Diana: Yes, I'd love that! It would be amazing. Gymnastics is my passion. It's all I have done for a lifetime. Gymnastics will always be special for me. And now that I for me. Interviewer: And so what keeps you from going back? Diana: Well, I don't know. I guess I am too old for gymnastics now [she is 22]. And if I did go back, I'd want to win, to get a result. To go back to get a $5^{\text {th }}$ or $6^{\text {th }}$ place, no, no way. I couldn’t do it.

Interviewer: Why is winning so important for you?

Diana: Well, you know, at some point you get to a level where mistakes are not allowed and being the best becomes a fundamental part of your life. It still is. When I was competing, my club was really strong and all of my teammates were winning national titles. Imagine what would have happened if I hadn’t won too? I would have felt inferior, worthless. I was the oldest of the group, the team captain: I had to win. And then when you win it’s just an amazing feeling! Once you are there, on the podium, with the national anthem playing for you; all the sacrifices, the tears, and the 
hard work disappears. It is such a valuable experience, better than anything else, even though 'normal' people cannot understand it.

Interviewer: Tell me about your life now, after gymnastics.

Diana: I am not doing anything really, it’s not like I have any reason to excel in something, you know, it just became a normal life. I have to admit that I do feel a little bit 'behind’ compared to others. I mean, they’ve had experiences I didn’t have: they've travelled, they've done different things, and I’ve done nothing. My boyfriend skis, snowboards, while I can’t even ride a bike! ... When I retired from gymnastics and stepped into the 'outside world' I felt like I had so much to learn. Even now, I still feel like I am chasing everything. And I don’t like it. I don’t like to be behind. I was used to be in the front. I'm used to winning.

Despite it being four years since she retired, Diana's life is still ruled by the same values and norms learned from gymnastics: the importance of winning and being perfect, the importance of hard work and discipline. The way she describes her life as a gymnast aligns with Douglas and Carless’ (2006) performance narrative, where athletes present a monological and linear narrative, solely focusing on sport performance and success. The post-retirement entangled narrative identified in this study observes the same linearity and focuses on the same cultural values. Nevertheless, as Richardson (2000) suggested, 'if the available narrative is limiting or at odds with the actual life, people's lives end up being limited' (p. 213). Such is the effect of Diana's narrative: it appears to be limiting her circumstances, keeping her from experimenting, trying to find new opportunities in her life. The perspective of the entangled narrative is on the past, it is strongly intertwined with the gymnast's previous self and associated values, but also with the knowledge that going back is impossible. This impossibility creates a narrative wreckage that leaves the storyteller seemingly frozen in time, incapable of moving forward or exploring an alternative 
1 life after gymnastics. The metaphor of the storyteller being 'shipwrecked' by the storm of

2 what happens in his/her life is commonly used in narrative psychology to represent those that

3 do not always fit the reality they live in (Frank 2013). This wreckage creates a lack of

4 coherency in one's narrative, which can only be overcome by finding a new, better fitting

5 story.

6 The challenge of finding a new story, though, seems overwhelming for Diana, who

7 has only ever identified herself as a gymnast. This inability to flourish post-retirement

8 resonates with the construct of psychological well-being (PWB; Ryff 1989). PWB is a

9 multidimensional construct that focuses on human development and individual's potential for

10 a meaningful life and self-realisation (Keyes et al. 2002). Diana’s entangled narrative appears

11 to leave her struggling to satisfy the proposed dimensions of PWB; she is unsatisfied with herself and unable to accept her own limits (i.e., self-acceptance), as shown by her statement,

13 'I don't like to be behind. I was used to be in front. I'm used to winning'. This lack of self-

14 acceptance also impacts on her feelings of being unable to shape her own environment to

15 meet her needs (i.e., environmental mastery), as exemplified by her perception of 'having so

16 much to learn' and to be 'still chasing everything'. Diana has no goals, aspirations, passions

17 or interests outside of gymnastics. As a result, she lacks a sense of purpose and meaning in

18 life and continues to ruminate about old times (i.e., purpose in life and personal growth), as

19 observed when she stated, 'now I am not doing anything really, it's not like I have any reason

20 to excel in something, you know, it just became a normal life'.

21 Other than the personal indicators of PWB, the struggle in reconciling with the

22 changes in her life also seems to play a role from the perspective of Diana's social well-

23 being, defined as ‘the appraisal of one's circumstances and functioning in society' (Social

24 WB; Keyes 1998, p. 122). Although she has few close and trusting relationships with others

25 who are not gymnasts, if she does speak to 'normal' people - as she describes them (i.e., non- 
1 gymnasts) - she struggles to accept them if they do not share her values (i.e., social

2 acceptance) and also sees herself as an outsider or an intruder in their environment (i.e.,

3 perceived lack of social integration). Yet, despite retaining these values and norms in

4 retirement, she also secretly envies others who have interests and experiences that do not

5 align with her own and have clear goals and objectives in life, which can be explained using

6 social comparison theory (Festinger 1954). Indeed, when Diana was a gymnast she used to

7 make downward comparisons to 'normal' people; they are not as successful as me because

8 they have not achieved as much as I have (e.g., trophies, medal). Nevertheless, since her

9 retirement, she makes upward comparisons; they have more life experiences than I have,

10 which accounts for why she is envious.

11 Diana's narrative is characterised by these and other tensions; she acknolwedges that

12 she has to develop an identity and life outside of gymnastics, but she feels she does not know

13 how to do it. Indeed, narratives which contain significant tensions or conflict can be difficult

14 to both tell and hear, says Frank (2013), and as result they are often silenced. The tensions in

15 Diana's story are brought to light during our interviews, which were at times hard for Diana,

16 with tears shed, but also difficult for the interviewer to hear. Her negative feelings and lack of

17 positive affect hint at low levels of subjective well-being (SWB), defined in the literature as

18 an indicator of life quality, composed by life satisfaction and happiness (Lundqvist 2011).

19 Diana keeps thinking at her old life as a gymnast, describing it as a happy time, where every

20 moment is positive. Compared to her recall of the gymnastics experience, nothing in her

21 current life seems to make her happy again. Her current work as a coach does not help her to

22 move on with her life, leaving her unsatisfied and longing for her past. The idea of being

23 'normal' itself seems to be a negative concept for Diana, for whom the only way to feel

24 worthy is by being the best. This type of narrative keeps Diana 'chained' to an idealised past,

25 which precludes her from continuing with her life in a way that might promote well-being. 


\section{The Going Forward Narrative: Giorgia's story}

Giorgia remembers having always been different from most gymnasts. Although

3 passionate about gymnastics, and embracing all the values and norms that went along with

4 being an elite athlete, she also had other friendship circles away from gymnastics. When

5 competing and training, she recalls being dedicated, disciplined, pushing through the pain

6 barrier, and developing strong relationships with other gymnasts; she believed such

7 behaviours led her to win a number of national events and enjoy her gymnastics career. She

8 loved her sport, and was passionate and excited about mastering new skills and routines.

9 Nevertheless, away from her sport, she would spend time with friends from school who were

10 not gymnasts, and considered herself to be open to new experiences. From an early age,

11 Giorgia had a clear purpose in life, and always knew what she wanted to be when she was

12 older.

13 Interviewer: So, it's been now almost three years out of gymnastics. What are your

14 memories of those times?

15 Giorgia: I always enjoyed being in the gym. It was fun. And I always had a good

16 group of teammates. We had such an intense relationship, I mean, we were always

17 together, training and competing. But I was never competitive towards them. I also

18 had friends in school, though. And I had a good relationship with my coaches too. I

19 knew they cared about me and I cared about them, even though there might have been

20 some misunderstandings every now and then. Still, I had a great experience but this

21 was never what I wanted to do with my life. I have always wanted to become a

22 doctor, so I can't picture my future as a coach. I am applying to go on Erasmus next

23 year, and then I will finish my Medical studies and specialise in cardio-surgery.

24 Interviewer: So no more gymnastics for you in your life? 
Giorgia: Well, you know, gymnastics gives you an education that's extreme. I mean, you can't easily shrug it off because it’s almost as if it goes inside your cells, becomes part of you. And you just get so used to all those mechanisms, all those ways. I mean, the rigorous planning of trainings, with their inflexible and repetitive structure: warm up, body elements, throws and then routines; repetitive, yes, but also safe, under control, something that you know how it works. And this does push you to plan in running towards her future, for which she has plans, hopes and dreams. Despite growing up in a gymnastics environment similar to Diana’s, Giorgia never identified with the performance narrative, looking at her teammates and coaches as more than just competitors and leaders, but appreciating the relationship developed with them. At the same time, Giorgia 
1 with the clear goal of becoming a doctor; she was a friend, and a daughter. These varied

2 aspects of Giorgia’s life as a gymnast relate to Douglas and Carless' (2006) description of a

3 discovery narrative. Athletes describing this narrative present a story of exploration, which

4 goes over and above performance outcomes. The open attitude towards discovery that

5 Giorgia adopted as a gymnast, characterised by a variety of goals in life and positive

6 relationships with others, played an important role in shaping her experience of transitioning

7 to retirement from gymnastics. Research in the literature suggests that key mediators of a

8 successful retirement are social support during transition and the presence of alternative

9 identities (e.g., Lally 2007; Lavallee and Robinson 2007; Park et al. 2013). Thanks to the

10 discovery narrative she embraced as an athlete, Giorgia appears to be able to develop it into a

11 going forward narrative in her post-retirement years.

Contrary to Diana’s entangled narrative, the going forward narrative appears to support several aspects related to well-being in Giorgia’s life following gymnastics. Indeed,

14 well-being researchers have emphasised the role of global well-being (SWB, PWB and Social

15 WB) as a protective factor for challenges derived from the sport environment, such as

16 retirement from sport (Lundqvist and Sandin 2014). In line with the different dimensions of

17 PWB (Ryff 1989), Giorgia has been able to accept the end of her gymnastics career and to turn her energies into new goals (i.e., autonomy, purpose in life, and personal growth). From

19 the point of view of Social WB, Giorgia has been able to value her relationship and to 20 integrate in different social circles, as she herself describes: 'I always had a good group of 21 teammates. [...] I also had friends in school, though. And I had a good relationship with my 22 coaches too. I knew they cared about me and I cared about them'. These behaviours show aspects of social integration, social acceptance and social values (Keyes 1998). Unlike Diana’s narrative, which revealed tensions that endangered her SWB,

25 Giorgia’s narrative contains no narrative tensions associated with her retirement from 
1 gymnastics. Giorgia is critically aware throughout her story of the negative and positive

2 aspects of her gymnastics experience. Moreover, and unlike Diana’s entangled narrative,

3 Giorgia's memory of gymnastics is not perfect and idealised, but she still recognises its

4 importance for her life and her love for the sport. This critical awareness of her experience

5 helps Giorgia build on it, taking the best out of her gymnastics years and use them to help her

6 to thrive into her new life outside of gymnastics.

\section{$7 \quad$ The Making Sense Narrative: Elisabetta's story}

Elisabetta describes herself as a former gymnast. She had a successful career, winning and competing at regional and national events. When asked to describe her past, she looked back on her career with fond memories. Memories of past wins, memories of a tough but safe environment, memories of close relationships with other gymnasts and of a strict, yet respected and beloved coach. She reported spending a great deal of her spare time and efforts honing her skills and routines after school to be successful, adhering to the values of the club.

She described her early life as very focused and goal-oriented, with no time for novel experiences. Following retirement, Elisabetta spent a long time coming to terms with it. Initially she felt a sense of freedom, breaking away from her former regimented life. Then the novelty of it faded away and Elisabetta was left with a hole. Like Diana, Elisabetta missed gymnastics and wished she could go back to the safe and structured environment she knew well. The unpredictability of her new life (e.g., new school, new friends, new interests) scared her, but her fear was not enough to keep her from trying and in the end Elisabetta started to make new friends outside of gymnastics and replaced gymnastics with another passion: that! After years of running around, with my life planned to the minute, I felt free. I 
went to University and that was everything I did. Lectures in the morning, home on the sofa in the afternoon. Complete relaxation! But after a few months my body was going crazy, I felt I needed to move. And I started to miss gymnastics. There was a time when I kept asking myself 'Why? Why did I do it? Why did I quit?’ But I knew why, I was tired of being on my own, the only Senior in the club, always working by myself, with no one to share a laugh or a bad moment. In the gym things hadn’t changed, so it made no sense to go back. I had to stick to my choice and look forward, so I started dancing.

Interviewer: And what was the world outside of gymnastics like? Elisabetta: Well, you know, at the beginning it wasn't easy. I felt lost in a world that I didn’t know. I always imagined that once I quit gymnastics I would have spent a lot of time with friends, going out, having fun. But my friends from high school knew how my life used to be: no going out during the week because I had training, no going out on Saturday night because I had competitions on Sunday. After a while they stopped asking me to go out with them, so, in the beginning I was on my own; I had no one to go out with. Saturday nights weren't exactly like I imagined! But then over time, at University, I met new people, made new friends and things started going differently. Interviewer: And then you mentioned dance! Another new experience...

Elisabetta: Well, I believe dance will never make me feel like gymnastics did. And the relationship with my dance teacher will never be like the one with my coach. It is different. I respected my coach. It was a hierarchical relationship, she would tell me what to do and I would do it. I respected her, listened to her, even when she was angry at me and I didn’t want to listen. I did, without talking back. But I also knew she would have been there for me if I needed her. It was a strong bond. With the dance teacher it is different. Yes, there is respect, but she does not tell us what to do, she 
asks what we think and people even dare complain if she asks you to do something. You can’t do that!

Compared to Giorgia’s narrative, Elisabetta’s story is less projected to the future, for which she has no real plans. She is starting to make friends with others outside of her gymnastics circles and speaks to them about their attitudes, opinions, passions and careers yet she struggles to tell them about her own thoughts and goals, as she has yet to formulate them. Elisabetta recounts this emerging narrative as challenging when developing new relationships, and it can make her feel isolated and frustrated with herself as she thinks back to her old, safe gymnastics life. When she is in a new environment Elisabetta still looks back to the values learnt as a gymnast, tightly holding on to both positive and negative experiences, not yet ready to let them go and to build new ones.

In line with Smith’s (2013) concept of emergent narrative, Elisabetta’s making-sense narrative is undefined, without a clear storyline, and only a slight tension between the fascination with the safety of the past and the hopes - not yet turned into plans - for what the future might hold. Frank (2013) argued before that it is possible for an individual to tell different, sometimes even opposing narratives, alternately. Narratives should not be thought to be mutually exclusive; instead their ability to coexist depends on the narrative's degree of stability (Papathomas and Lavallee 2012). The lower the stability, the higher the possibility the storyteller switches from one narrative to the other, while figuring out their own selfstory, just as Elisabetta appears to be. While recounting her story she is focused on her present and does not have a clear vision of the future. She has no plans or hopes for future jobs, unlike Giorgia and similar to Diana. Yet, differently from Diana, Elisabetta is open to new possibilities. Her narrative appears to place her in a transitory space, where she has not yet developed the skills to be like Giorgia, who is going forward, but is also not entangled and chained to the past like Diana. 
2 with her life. She is very much focused on a present where she feels quite happy, even though

3 she lacks Giorgia's energetic enthusiasm for what is to come. Indeed, despite the intervening

4 years since her retirement, Elisabetta still has no clarity regarding what is to come. Therefore,

5 in terms of PWB, she has no clear ideas related to her personal growth and meaning in life.

6 Socially, she is slower than Giorgia to integrate herself with the community surrounding her

7 (Social WB). Like Diana, she struggles to adapt to the 'outside world', but still manages to

8 make new friends. She continues to explore, and every now and then, when she does not like

9 what she is experiencing (e.g., the different, democratic way of her dance teacher), she runs

10 back to the 'perfect' memory of gymnastics. The uncertainty of the making sense narrative

11 positions this typology in a liminal space (Bruce et al. 2014), an in-between space

12 characterised by uncertainty, and conceptualised previously in studies of narrative (e.g.,

13 Broom and Cavenagh 2011, Bruce et al. 2014). In this space people are 'neither one thing or

14 another; or maybe both' (Turner 1967, p. 96). McAdams, Josselson, and Lieblich (2006) have

15 linked the experience of liminality to the uncertainty caused by disruption in identity and

16 personal narrative. This uncertainty of the lived experience is difficult to describe in a story,

17 revealing the existence of an unsayable side of this narrative (Rogers et al. 1999). Therefore,

18 Elisabetta's narrative remains in this liminal space, overlapping in some points with the other

19 two narratives, waiting to evolve, in one or in the other.

\section{Conclusions}

21 The aim of this study was to explore how former gymnasts adjust to retirement from

22 gymnastics. By conducting and analysing the short life-history interviews of eight former

23 competitive gymnasts, we identified three narrative typologies: Entangled Narrative, Going

24 Forward Narrative, and Making Sense Narrative. The contribution to the literature of these 
1 narrative types is twofold. Firstly, they expand on Douglas and Carless' (2006) research on

2 narratives in sport. While these authors' work mainly focuses on the narrative athletes adopt

3 during their sport career, the present study illuminates how this narrative develops once

4 athletes retire from sport and what consequences they can have for those who embody them.

5 The going forward narrative has commonality with Douglas and Carless' (2006) description

6 of discovery narrative. As a result of an athlete's discovery narrative, in the going forward

7 narrative all the different elements that the athlete has been interested in other than sport

8 come together to form a balanced and well-integrated life story that builds on the past

9 discoveries to look toward current and future ones. On the other hand, the entangled narrative

10 shows the consequences of the linear, monological, and outcome-focused performance

11 narrative. While the cultural values remain the same, the outlook changes. That is, the performance narrative mainly focuses on the present in terms of 'person as only an athlete' and on the future in terms of working toward future goals and successes. Alternatively, the entangled narrative shows a strong tendency to look backward, to a past that represents the only kind of person the individual sees him/herself able to be. Being stuck in the past and in the cultural values of the performance narrative keeps individuals from moving forward and growing in their life following sport.

The main difference between the performance/entangled narratives and the discovery/going forward narratives is their tellability. That is, one of the dimensions of narrative, which is negotiated between teller and listener depending on the particular context

21 (Ochs and Capps 2001). Carless and Douglas (2013b) describe the performance narrative as the dominant narrative type in sport, the one widely accepted and encouraged. They investigate how athletes can relate to this narrative in different ways, by living, resisting, or

24 playing the part of the athlete (Carless and Douglas 2013b). While the performance narrative

25 is the one that is encouraged and recounted, other narrative types (i.e., discovery and 
1 relational) are discouraged, marginalised and often silenced. When looking at post-athletic

2 retirement narratives, though, it seems that the one still looking at the same values of the

3 performance narrative is now silenced. Individuals showing an entangled narrative do not feel

4 free to share their insecurities in a constructive way, and often silence or suppress their 'real'

5 feelings. The entangled narrative becomes the one that no one wants to hear, as it brings to

6 light pain, sufferance, the necessity for emotional labour, and a striving to fit in and adapt to

7 life. On the other hand, the going forward narrative differs from the discovery one because it

8 becomes the story many people are fascinated by and aspire to: successful, free, open, and

9 empowered. Following years of struggles against the dominant narrative, these individuals

10 are the ones whose stories many people want to hear.

11 The second contribution of the present study to the literature is related to the different post-retirement narratives. These narratives offer new resources for supporting athletes during their experience of retirement. Specifically, by showcasing a range of lived experiences of retirement, they might allow former gymnasts to appreciate the existence of alternative stories than the one they tell. Douglas and Carless (2009b) describe how the use of stories with students can support reflective practice and facilitate change in both individuals and groups. In line with Smith and Sparkes' (2009) suggestion, by expanding an individual's narrative repertoire, we, as practitioners, could enhance their flexibility and offer them an opportunity to live their life differently. Being able to see and adopt a new and more functional narrative might, in turn, enhance former gymnasts’ future well-being.

In order to effectively enhance athletes' well-being, researchers should seek to better understand what enables some athletes to transition from one type of narrative to a more functional one. Is it 'just' a matter of time? The participants in this study presented a wide range of time since retirement, spanning from 1 to 17 years, still the amount of time did not seem to affect the development of their narratives. Denzin (1989) suggested that the catalyst 
1 of change is often an epiphany, which in this context he described as a difficult and often

2 painful time that marks and changes an individual. This perspective is supported by Douglas

3 and Carless (2009a), who discussed how two former professional golfers were able to

4 abandon the performance narrative only following personal challenges (i.e., sickness of a

5 parent and a diagnosis of clinical depression in the former athlete herself). In a similar way,

6 those participants in our study who presented a discovery narrative, all faced painful personal

7 experiences (e.g., loss of a parent, hospitalisation due to eating disorders, panic attacks)

8 which required them to work with a psychotherapist or psychologist. It is possible that this

9 further experience provided them with a space to reflect on themselves, an asylum, as

10 Douglas and Carless (2009a) described, or 'a place of refuge where performance values were

11 no longer paramount' (p. 226). While the aim of the present study was not to answer why

12 gymnasts develop one type of narrative instead of another, we would encourage scholars to

13 investigate the individuals (e.g., parents, coaches, teammates) and artefacts (e.g., medals,

14 leotards, pictures) within athletes' socio-cultural environment that influence athletes’

15 adherence to an Entangled, Making Sense, or Discovery narrative.

17 Word Count: 7858 words

\section{References}

20 Alfermann, D., 2000. Causes and consequences of sport career termination. In D. Lavallee and P. Wylleman, eds. Career transitions in sport: International perspectives. Morgantown, WV: Fitness Information Technology, 45-58.

23 Atkinson, R., 1998. The life story interview. London: Sage. 
1 Barker-Ruchti, N. and Schubring, A., 2016. Moving into and out of high-performance sport: The cultural learning of an artistic gymnast. Physical Education and Sport Pedagogy, 21 (1), 69-80. doi: 10.1080/17408989.2014.990371.

Berger, R., 2015. Now I see it, now I don’t: Researcher’s position and reflexivity in qualitative research. Qualitative Research, 15 (2), 219-234.

6 Broom, A. and Cavenagh, J., 2011. On the meanings and experiences of living and dying in 7 an Australian hospice. Health, 15 (1), 96-111. doi: 10.1177/1363459309360797.

Bruce, A., Sheilds, L., Molzahn, A. and Beuthin, R., 2014. Stories of liminality: living with life-threatening illness. Journal of Holistic Nursing, 32 (1), 35-43. doi: 10.1177/0898010113498823.

Caddick, N., 2016. Doing narrative analysis. In: E. Lyons and A. Coyle, eds. Analysing qualitative data in psychology. $2^{\text {nd }}$ ed. London: Sage, 222-239.

Carless, D. and Douglas, K., 2013a. “In the Boat” but “Selling Myself Short”: Stories, narratives, and identity development in elite sport. The Sport Psychologist, 27, 27-39.

Carless, D. and Douglas, K., 2013b. Living, resisting, and playing the part of athlete: Narrative tensions in elite sport. Psychology of Sport and Exercise, 14, 701-708. doi: 10.1016/j.psychsport.2013.05.003.

Cavallerio, F., Wadey, R. and Wagstaff, C.R.D., 2016. Understanding overuse injuries in rhythmic gymnastics. Psychology of Sport and Exercise, 25, 100-109. doi: 10.1016/j.psychsport.2016.05.002.

Clowes, H., Lindsay, P., Fawcett, L. and Knowles, Z., 2015. Experiences of the pre- and post-retirement period of female elite artistic gymnasts: An exploratory study. Sport \& Exercise Psychology Review, 11 (2), 4-21.

Crossley, M. L., 2000. Introducing narrative psychology: Self, trauma and the construction of meaning. Buckingham: Open University Press. 
1 Denzin, N. K., 1989. Interpretive biography. London: Sage.

2 Douglas, K. and Carless, D., 2006. Performance, discovery, and relational narratives among women professional tournament golfers. Women in Sport and Physical Activity Journal, 15 (2), 14-27.

Douglas, K. and Carless, D., 2009a. Abandoning the performance narrative: Two women’s stories of transition from professional sport. Journal of Applied Sport Psychology, 21, 213-230. doi: 10.1080/10413200902795109.

Douglas, K. and Carless, D., 2009b. Exploring taboo issues in professional sport through a fictional approach. Reflective Practice, 10 (3), 311-323. doi: $10.1080 / 14623940903034630$

Festinger, L., 1954. A theory of social comparison processes. Human Relations, 7 (2), 117140. doi: $10.1177 / 001872675400700202$.

Frank, A. W., 2010. Letting stories breathe: A socio-narratology. Chicago: The University of Chicago Press.

Frank, A. W., 2012. Practicing dialogical narrative analysis. In: J. Holstein and J. Gubrium, eds. Varieties of narrative analysis. Los Angeles, CA: Sage, 33-52.

Frank, A. W., 2013. The wounded storyteller: Body, illness, and ethics, $2^{\text {nd }}$ edition. Chicago: The University of Chicago Press.

Kerr, G., Berman, E. and De Souza, M. J., 2006. Disordered eating in women’s gymnastics: Perspectives of athletes, coaches, parents, and judges. Journal of Applied Sport Psychology, 18 (1), 28-43. doi: 10.1080/10413200500471301.

Kerr, G. and Dacyshyn, A., 2000. The retirement experiences of elite female gymnasts. Journal of Applied Sport Psychology, 12 (2), 115-133. doi: 10.1080/10413200008404218.

Keyes, C. L. M., 1998. Social well-being. Social Psychological Quarterly, 61, 121-140. 
1 Keyes, C. L. M., Shmotkin, D. and Ryff, C. D., 2002. Optimizing well-being: The empirical encounter of two traditions. Journal of Personality and Social Psychology, 82 (6), 1007-1022. doi: 10.1037//0022-3514.82.6.1007

Lally, P., 2007. Identity and athletic retirement: A prospective study. Psychology of Sport and Exercise, 8, 85-99. doi: 10.1016/j.psychsport.2006.03.

6 Lavallee, D. and Robinson, H. K., 2007. In pursuit of an identity: A qualitative exploration of 7 retirement from women’s artistic gymnastics. Psychology of Sport and Exercise, 8, 119-141. doi: 10.1016/j.psychsport.2006.05.003.

Lieblich, A., Tuval-Maschiach, R. and Zilber, T., 1998. Narrative research: Reading, analysis and interpretation. London: Sage.

Lundqvist, C., 2011. Well-being in competitive sports - The feel-god factor? A review of conceptual considerations of well-being. International Review of Sport and Exercise Psychology, 4 (2), 109-127. doi: 10.1080/1750984X.2011.584067.

Lundqvist, C. and Sandin, F., 2014. Well-being in elite sport: Dimensions of hedonic and eudaimonic well-being among elite orienteers. The Sport Psychologist, 28, 245-254.

McAdams, D. P., 1993. The stories we live by. New York: The Guilford Press.

McAdams, D. P., 2001. The psychology of life stories. Review of General Psychology, 5 (2), 100-122. doi: 10.1037//1089-2680.5.2.100.

McAdams, D. P., 2008. The Life Story Interview [online]. Available from: https://www.sesp.northwestern.edu/docs/Interviewrevised95.pdf

McAdams, D. P., Josselson, R. and Lieblich, A., 2013. Identity and story: Creating self in narrative. Washington, DC: American Psychological Association. Sport and Exercise, 17, 79-87. doi: 10.1016/j.psychsport.2014.07.010. 
1 McKenna, J., and Thomas, H., 2007. Enduring injustice: a case study of retirement from professional rugby union. Sport, Education and Society, 12 (1), 19-35. doi: 10.1080/13573320601081500.

McLeod, J., 1997. Narrative and psychotherapy. London: Sage.

Ochs, E. and Capps, L., 2001. Living narrative. Cambridge, MA: Harvard University Press.

O’Reilly, M. and Parker, N., 2013. ‘Unsatisfactory saturation’: A critical exploration of the notion of saturated sample sizes in qualitative research. Qualitative Research, 13 (2), 190-197.

Papathomas, A. and Lavallee, D., 2012. Narrative constructions of anorexia and abuse: An athlete’s search for meaning in trauma. Journal of Loss and Trauma, 17 (4), 293-318.

Park, S., Lavallee, D. and Tod, D., 2013. Athletes’ career transition out of sport: A systematic review. International Review of Sport and Exercise Psychology, 6 (1), 22-53. doi: 10.1080/1750984X.2012.687053.

Phoenix, C. and Smith, B., 2011. Telling a (good?) counter-story of aging: Natural bodybuilding meets the narrative of decline. The Journals of Gerontology Series B:

Plummer, K., 2001. Documents of life 2. Thousand Oaks, CA: Sage.

Richardson, L., 2000. Writing: A method of inquiry. In: N. Denzin and Y. Lincoln, eds. Handbook of qualitative research. $2^{\text {nd }}$ ed. London: Sage, 959-978.

Rogers, A.G., et al., 1999. An Interpretive Poetics of Languages of the Unsayable. In: Josselson, R. and Lieblich, A, eds. The Narrative Study of Lives: Making meaning of narratives. Thousand Oaks, CA: Sage, 77-106.

Ryff, C. D., 1989. Happiness is everything, or is it? Exploration on the meaning of psychological well-being. Journal of Personality and Social Psychology, 57, 141-166.

Smith, B., 2010. Narrative inquiry: Ongoing conversations and questions for sport and 
exercise psychology research. International Review of Sport and Exercise Psychology, 3 (1), 87-107.

Smith, B., 2013. Disability, sport and men's narratives of health: A qualitative study. Health Psychology, 32 (1), 110-119. doi: 10.1037/a0029187.

Smith, B., 2016. Narrative analysis. In: E. Lyons and A. Coyle, eds. Analysing qualitative data in psychology. $2^{\text {nd }}$ ed. London: Sage, 202-221.

Smith, B. and Sparkes, A. C., 2009. Narrative inquiry in sport and exercise psychology: What can it mean, and why might we do it? Psychology of Sport and Exercise, 10, 1-11. doi: 10.1016/j.psychsport.2008.01.004.

Sparkes, A.C. and Smith, B., 2014. Qualitative research methods in sport, exercise and health. London: Routledge.

Stirling, A. E., Cruz, L. C. and Kerr, G. A., 2012. Influence of retirement on body satisfaction and weight control behaviors: Perceptions of elite rhythmic gymnasts. Journal of Applied Sport Psychology, 24 (2), 129-143. doi: 10.1080/10413200.2011.608413.

Turner, V., 1967. The forest of symbols: Aspects of Ndembu ritual. Ithaca, NY: Cornell University Press.

Warriner, K. and Lavallee, D., 2008. The retirement experiences of elite female gymnasts: Self-identity and the physical self. Journal of Applied Sport Psychology, 20, 301-317. doi: 10.1080/10413200801998564.

Wray, N., Markovic, M. and Manderson, L., 2007. “Researcher saturation”: The impact of data triangulation and intensive-research practices on the researcher and qualitative research process. Qualitative Health Research, 17 (10), 1392-1402. doi: 10.1177/1049732307308308. 